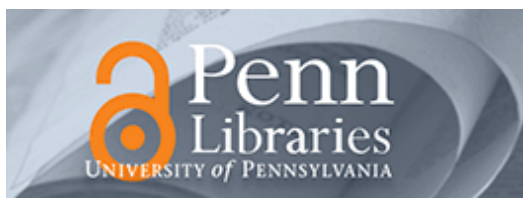

University of Pennsylvania ScholarlyCommons

1990

\title{
Changing Risk, Changing Risk Premiums, and Dividend Yield Effects
}

Nai-Fu Chen

Bruce Grundy

Robert F. Stambaugh

University of Pennsylvania

Follow this and additional works at: http://repository.upenn.edu/fnce_papers

Part of the Finance and Financial Management Commons

\section{Recommended Citation}

Chen, N., Grundy, B., \& Stambaugh, R. F. (1990). Changing Risk, Changing Risk Premiums, and Dividend Yield Effects. The Journal of Business, 63 (1), S51-S70. Retrieved from http://repository.upenn.edu/fnce_papers/411 


\title{
Changing Risk, Changing Risk Premiums, and Dividend Yield Effects
}

\begin{abstract}
We investigate the cross-sectional relation between dividend yield and expected return and attempt to include various effects of changing risk measures and changing risk premiums. A stock's risk is measured by its sensitivities to two factors, a market factor and a changing-risk-premium factor. After analyzing dividendrelated changes in risk measures, we investigate the presence of dividend effects in expected returns using four methods, each imposing a different structure on the temporal behavior of risk measures and risk premiums. For each method, we find no reliable cross-sectional relation between dividend yield and risk-adjusted expected return.
\end{abstract}

\section{Disciplines}

Finance and Financial Management 


\section{Bruce Grundy}

Stanford University

\section{Robert F. Stambaugh}

University of Pennsylvania

\section{Changing Risk, Changing Risk Premiums, and Dividend Yield Effects*}

\section{Introduction}

A question of fundamental importance in corporate finance is whether a firm's dividend policy affects its value. In a world without taxes, transaction costs, information asymmetries, and other market imperfections, Miller and Modigliani (1961) show that a firm's value is invariant with respect to its dividend policy. Their conclusion may still apply in a world where dividends and capital gains are taxed differently-whether explicitly in terms of tax rates or implicitly because capital gains can be accumulated before tax until realized-provided investors and firms are free to adjust optimally in the induced equilibrium. ${ }^{1}$

* We thank K. C. Chan, Don Keim, Merton Miller, and the participants at the Merton Miller Conference in Maui, June 1988, for helpful comments and suggestions, Raymond Kan for computational assistance, and the Center for Research in Security Prices and Batterymarch Financial Management for support.

1. Black and Scholes (1974) and Miller and Scholes (1978) discuss scenarios in which differential taxes do not lead to differential pricing of dividends vs. capital gains. Brennan (1970) and Litzenberger and Ramaswamy (1979) present models in which dividends receive a lower relative price.

(Journal of Business, 1990, vol. 63, no. 1, pt. 2)

(C) 1990 by The University of Chicago. All rights reserved. 0021-9398/90/6301-0013\$01.50
We investigate the cross-sectional relation between dividend yield and expected return and attempt to include various effects of changing risk measures and changing risk premiums. A stock's risk is measured by its sensitivities to two factors, a market factor and a changing-risk-premium factor. After analyzing dividend-related changes in risk measures, we investigate the presence of dividend effects in expected returns using four methods, each imposing a different structure on the temporal behavior of risk measures and risk premiums. For each method, we find no reliable cross-sectional relation between dividend yield and riskadjusted expected return. 
Unfortunately, there is little agreement among researchers whether such an equilibrium obtains. The purpose of this empirical study is to provide some new insight into this classical problem by taking into account some recent evidence on asset pricing.

There are at least two approaches to investigating whether the dividend policy of a firm affects its value. We can examine the differences in return between ex- and non-ex-dividend periods and make inferences about the relative price (hence the tax penalty) of a dollar in cash dividend to a dollar in capital gain. Alternatively, we can ask whether cross-sectional differences in average return on stocks are related to differences in dividend policy after controlling for risk. In this section, we begin by reviewing, and to some extent reconciling, the existing empirical evidence on the relation between yield and return, and then we explain why we adopt the empirical design used in this study.

\section{A. Studies of Differences in Returns between Ex- and Non-Ex-Dividend Periods}

Even if equilibrium expected returns over a quarter are unaffected by dividend policy, the payment of dividends may be relevant to investors. Investors in different tax brackets will potentially find it optimal to hold different portfolios of risky assets. Given those portfolio decisions, investors intending to trade the stock of a firm about to go exdividend will have an incentive to time their trades so as to receive or to avoid the dividend whenever their marginal rate of substitution between dividends and capital gains (their after-tax value of a dollar of dividends relative to a dollar of capital gains) differs from the market rate of exchange (the price adjustment per dollar of dividends). Arbitrageurs whose relative valuation differs from the market's by more than their transactions costs will have incentives to undertake short-term trading.

In equilibrium, dividends will tend to flow to those who value them most highly. In the models of Green (1980) and Grundy (1985), the equilibrium price adjustment such that the market clears on each date surrounding the ex-date will not be confined to the ex-date alone. The price adjustment will reflect the tax status of the dividend in the hands of different classes of investors, the costs of accelerating and delaying planned trades, and the transactions costs of potential arbitrageurs.

The role of the marginal trader who shifts planned trades through time (vs. a short-term arbitrageur) is not entirely clear. Nevertheless, the empirical investigations of Elton and Gruber (1970), Kalay (1982, 1984), Lakonishok and Vermaelen (1983, 1986), Eades, Hess, and Kim (1984), and Elton, Gruber, and Rentzler (1984) document that dividends do leave their tracks in the returns data if one compares returns on a given stock around ex-dates to returns on that same stock during non-ex-periods. In a search for patterns in returns through time, each 
stock serves as its own control for risk, thereby obviating the need for a model of equilibrium returns.

Value-maximizing firms need not have an incentive to adjust the supply of dividends in response to ex-day-related patterns in returns. Most studies that investigate such patterns do not address the question of whether the required return over the complete quarter is affected by dividend policy. One interesting exception is Poterba's (1986) study of the pricing of the class A (stock dividend) and class B (cash dividend) shares of Citizens Utilities. Not only can the patterns in returns within a quarter be examined but also the prices of the two classes of otherwise equivalent stock can be compared directly. Poterba reports that ex-day returns on the cash-dividend shares exceed those on stockdividend shares, but this difference is more than offset by the lower returns on the cash-dividend shares over non-ex-dividend periods. Overall, the returns on the cash-dividend shares are slightly lower than those on the stock-dividend shares. Poterba also reports that both class A and class B shares sell for approximately the same multiple of dividends. If the case of Citizens Utilities is representative of how a firm's dividend policy affects its value, the evidence is consistent with the equilibrium-required return over a complete quarter being unrelated to dividend policy. However, without more exemplars like Citizens Utilities, the researcher must, by default, undertake a cross-sectional examination of the relation between average returns and dividend yields.

The above discussion also highlights the potential difficulty in interpreting the cross-sectional results in Litzenberger and Ramaswamy (1979, 1980, 1982), Miller and Scholes (1982), and Morgan (1982). In these studies, the dividend-yield coefficient, estimated using various measures of expected within-month dividend yield, may reflect both the potential dividend tax penalty and the difference in return between ex- and non-ex-dividend periods. If dividend-paying firms have lower returns (as in the case of Citizen's Utilities) over non-ex-dividend periods, when they are regarded as zero-yield stocks, but higher returns around ex-dividend periods, this would impart an upward bias in favor of a positive cross-sectional relation between return and yield even though the rate of return over an entire quarter might be independent of dividend policy.

\section{B. Studies of Differences in Return between High- and Low-Yield Stocks}

The studies of Black and Scholes (1974), Blume (1980), and Keim (1985) examine the differences in average returns between high- and low-yield stocks over time. Using quarterly returns and the FamaMacBeth methodology, Blume (1980) reports a U-shaped relation between returns adjusted for beta risk and dividend yield. A U-shaped relation is not necessarily inconsistent with a tax effect if there are 
short sales retrictions and both yield and beta clientele effects, as discussed in Litzenberger and Ramaswamy (1980). An alternative interpretation of the U-shaped relation is investigated in Keim (1985). Table 2 of Keim documents that small firms tend to concentrate in the zero- and high-yield portfolios, while large firms are overrepresented in the portfolios of stocks with low but positive yields. The size effect is then expected to induce a $U$-shaped relation between returns and dividend yields. Keim also shows that the January seasonal in the size effect manifests itself as a January seasonal in the U-shaped yield effect.

In order to determine whether yield has any marginal explanatory power beyond its ability to proxy for the size effect, Keim (1985) uses both yield and the natural log of size as explanatory variables in a Seemingly Unrelated Regression (SUR) framework. The estimated yield coefficient is reliably positive in both January and non-January months. The estimated coefficient on dividend yield will reflect both the effect of cross-sectional differences in yields at a point in time and the correlation between return and dividend yield over time.

\section{An Overview of the Empirical Design in This Study}

The above discussion suggests that it is important (i) to have an empirical design that avoids the difficulty in interpreting results contaminated by the trading pattern surrounding the ex-dividend dates and (ii) to employ an appropriate pricing model that accounts for the size effect. The dividend-yield measure we use is a "long-run" measure similar to those in Black and Scholes (1974), Blume (1980), and Keim (1985). The yield for a given stock is computed as the sum of dividends per share paid during the previous year divided by the share price at the beginning of the previous year. ${ }^{2}$ We compare the average "riskadjusted" returns for high- and low-yield stocks to determine whether there is a relation between cash dividends and required rates of return.

The main pricing model used throughout this study is a multifactor model (see Merton 1973; Ross 1976; and Cox, Ingersoll, and Ross 1985) that contains two risk measures. These risk measures are defined as the coefficients $\beta_{p(m)}$ and $\delta_{p}$ in the regression

$$
R_{p t}=\alpha_{p}+\beta_{p(m)} \mathrm{RVW}_{t}+\delta_{p} \mathrm{PREM}_{t}+\epsilon_{p t},
$$

where $R_{p t}$ is the return on portfolio $p$ in excess of the Treasury-bill rate, $\mathrm{RVW}_{t}$ is the return in excess of the Treasury-bill rate on the valueweighted portfolio of stocks on the New York Stock Exchange

2. We have also conducted the tests in Secs. III-VI with another dividend-yield measure. For each portfolio, we adjust our yield measure by the average difference (over time) between the ex post realized portfolio dividend yield (in the test period) and our portfolio-yield measure that is based only on ex ante information. The results using both measures are qualitatively the same. 
(NYSE), and $\mathrm{PREM}_{t}$ is the difference between the return on a portfolio of "junk" bonds, bonds rated by Moody's as below BAA, and the return on a long-term U.S. government bond. ${ }^{3}$

The variable PREM $_{t}$ is intended to capture changes in the expected premium on risky assets. Keim and Stambaugh (1986) find that yields on junk bonds, stated in excess of the Treasury-bill rate, can predict excess returns on a variety of assets. Thus, relative changes in the prices of junk bonds, which are essentially captured by $\mathrm{PREM}_{t}$, are related to changes in asset-risk premiums. When characteristics of the investment opportunity set, such as risk premiums, change over time, models of intertemporal asset pricing suggest that assets' expected returns may be related to the sensitivities of their returns to changes in those characteristics (see Merton 1973; Ross 1976; Cox, Ingersoll, and Ross 1985; and Chen, Roll, and Ross 1986). The coefficient $\delta_{p}$ in (1) is a measure of this sensitivity, or risk. Chan, Chen, and Hsieh (1985) conclude that risk measures defined with respect to $\mathrm{PREM}_{t}$ possess significant ability to explain cross-sectional differences in expected stock returns, including differences related to the firm-size effect. This evidence seems particularly relevant to an investigation of dividendyield effects, given Keim's (1985) evidence suggesting that the firmsize effect and the dividend-yield effect are interrelated.

To compare our results with the existing literature, we have also used the traditional capital asset pricing model (CAPM) to adjust for risk. The risk measure of portfolio $p$ in this case is the coefficient $\beta_{p}$ in the familiar market-model regression,

$$
R_{p t}=\alpha_{p}+\beta_{p} \mathrm{RVW}_{t}+\epsilon_{p t} .
$$

In this study the basic units of observation are monthly excess returns on portfolios formed on the basis of dividend yield and firm size. This portfolio-formation process is motivated in part by Keim's finding that there is a (negative) monotonic relation between the average dividend yield and the size of firms among the positive yield portfolios. A simultaneous two-way classification will, we hope, allow more precise measurement of the two effects, although further refinement is almost surely possible.

Before implementing direct tests of the yield effect, we first perform some analyses on the joint time-series properties of returns and dividend yields. We find that dividend yields are related to expected monthly returns over time, consistent with similar findings by Rozeff (1984) and Fama and French (1988). The magnitude of the dividendyield slope coefficient, however, suggests that this time-series relation

3. Monthly returns on bonds rated below BAA are obtained from Ibbotson Associates, Chicago. This series is available only through 1978. Consequently, the sample period for our tests ends in December 1978. 
is unlikely to be due solely to a tax effect. Changes in risk premiums or conditional risk measures (betas) that are associated with changes in dividend yield could also contribute to this time-series relation. If we model the relation between changes in risk measures and changes in dividend yields as linear, we find evidence that risk measures do, in fact, vary through time with dividend yield.

Section II presents results indicating that expected returns and conditional risk measures are related to dividend yield over time. Section III examines the yield effect using the Seemingly Unrelated Regression (SUR) framework. Section IV uses a Fama-MacBeth-type (1973) twostep approach, which, as we discuss, has potential advantages under certain forms of dividend-related changes in risk measures. In Section $\mathrm{V}$, we use a variant of the approach in Chan and Chen (1988), which assumes that the conditional risk measures are linear in the mean of the distribution of the conditional risk measures. Finally, Section VI investigates the presence of a yield effect while modeling explicitly the nature of dividend-related parameter changes. In each of the above four approaches, we find a positive cross-sectional yield effect when the single-factor (CAPM) model is used. The results are similar to those contained in many previous studies and therefore are not reported separately in the tables. ${ }^{4}$ As we noted above, such results may be confounded by the size effect. When the two-factor model is used for risk adjustment, the yield effect becomes statistically indistinguishable from zero in each of the four approaches. Section VII concludes our findings.

\section{Empirical Relations between Dividend Yield and Risk Measures}

Before turning to direct tests for dividend-yield effects in models that adjust for risk, we first examine some empirical associations between risk measures and dividend yields. The evidence presented in this section indicates that (i) dividend yields are associated cross-sectionally with various risk measures and (ii) variation over time in dividend yields is associated with time variation in risk measures. Such results suggest that disentangling a tax-induced dividend yield effect, if any, from the other effects that are associated with yield can be difficult.

We analyze monthly returns on portfolios that are formed at the end of each year using a simultaneous two-way classification based on dividend yield and firm size. The dividend yield for a given stock is computed as the sum of dividends per share paid during the previous year divided by the share price at the beginning of the previous year.

4. When the single factor (CAPM) is used, the estimated yield coefficients corresponding to the methodologies in Secs. III-VI are (with $t$-statistics) $0.37(2.31)$, $0.86(2.17), 1.73(3.84)$, and $0.63(3.91)$, respectively. 
Firm size is computed as the total market value of the firm's outstanding common stock at the end of the previous year.

At the end of each year, beginning in December 1942, each firm on the NYSE with (i) complete return data available for the previous 5 years and (ii) a positive dividend yield is classified into one of 20 portfolios. The 20 portfolios are defined by quintiles of market value and by quartiles of dividend yield. The "zero-yield" firms, those paying no dividends during the previous year, are excluded from the tests for dividend-yield effects. ${ }^{5}$ The returns on the stocks within a portfolio are weighted equally each month. Since the assignment of firms to portfolios is done simultaneously with respect to firm size and dividend yield, some portfolios contain more firms than others. For example, the portfolio of firms in the highest yield quartile and the largest size quintile typically contains fewer firms than other portfolios. Nevertheless, there are no empty portfolios for the period beginning at the end of $1942 .^{6}$

We begin by examining pairwise cross-sectional correlations among average returns on the 20 portfolios, average dividend yields, and estimates of the risk measures defined in regressions (1) and (2). Table 1 reports these correlations for the overall 1943-78 period and for two subperiods. First, note that, in the overall period, the correlation between dividend yield and average return is 0.28 , but the correlations between dividend yield and the two market-beta estimates $\left(\hat{\beta}_{p}\right.$ and $\left.\hat{\beta}_{p(m)}\right)$ are -0.81 and -0.91 . In other words, dividend yield appears to be more strongly related to beta than to expected return. (Similar results occur in the subperiods.) In fact, if no risk measures are included, there is not a statistically reliable relation between expected return and dividend yield (similar to the findings of Blume [1980] and Miller and Scholes [1982]). If $\beta_{p}$ is included as the single important risk measure, however, then there appears to be a reliable positive relation between expected return and dividend yield. Thus, the cross-sectional relation between dividend yield and beta appears to play an important role in affecting inferences about the presence of a dividend-yield effect. We also note the strong positive correlation between average return and the estimated PREM-based risk measure $\hat{\delta}_{p}$ ( 0.96 in the overall period), which is consistent with previous evidence about the importance of this additional risk measure in explaining expected returns.

We next examine the association over time between risk measures

5. Evidence in previous studies suggest that the zero-yield group does not conform to any monotonic relation between dividend yield and expected return that might exist for the positive-yield stocks (e.g., Blume 1980 and Keim 1985). Since this study is most concerned with the sensitivity of inferences about such a monotonic relation, we chose to investigate this sensitivity within the sample of stocks for which monotonic relations have been documented in previous research.

6. This starting date is selected because earlier years produce some empty portfolios. 
TABLE 1 Correlations between Average Excess Returns, Average Dividend Yields, and Estimated Risk Measures for 20 Positive-Yield Portfolios

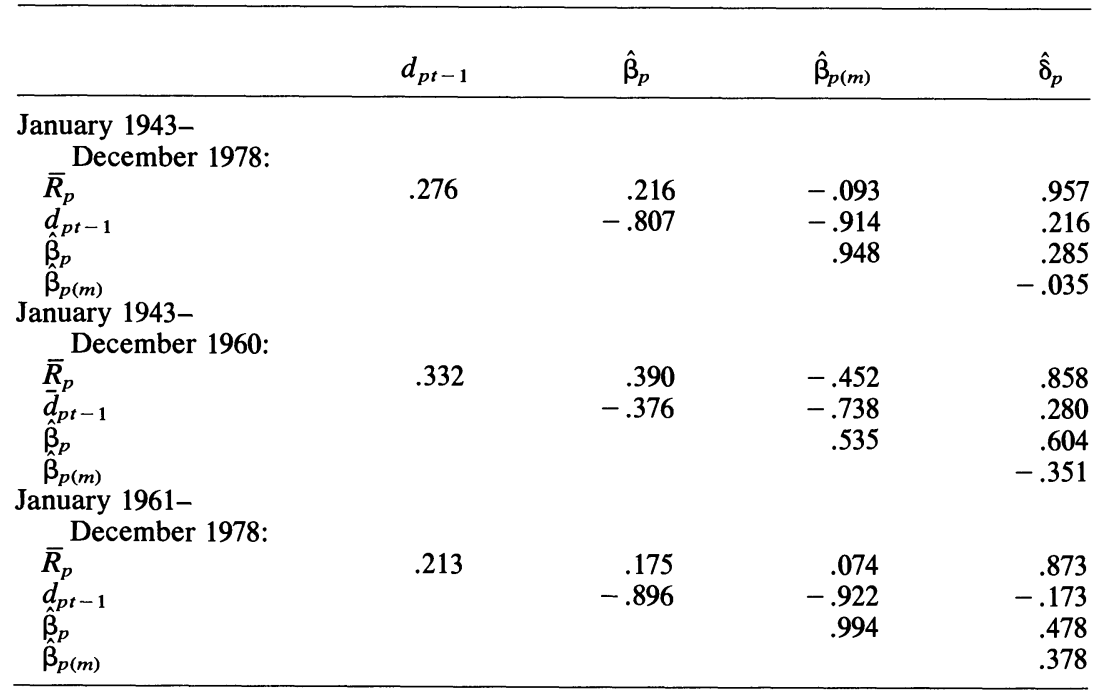

NoTE.-The variables are based on 20 equally weighted portfolios formed at the end of each year by sorting simultaneously on size and dividend yield. The variables are defined as follows:

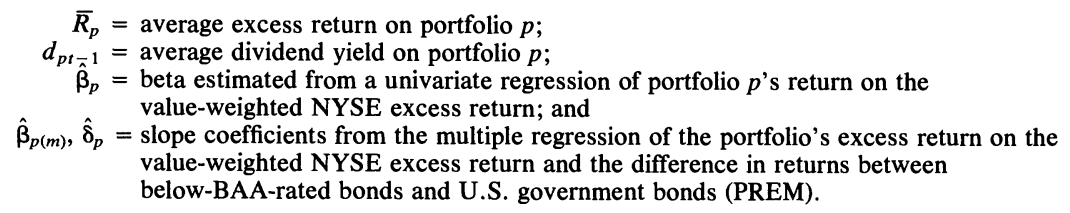

and dividend yield. To establish an initial point for comparison, we estimate the following regressions for each of the 20 positive-yield portfolios:

$$
R_{p t}=a_{0 p}+a_{1 p} \mathrm{RVW}_{t}+a_{2 p} \mathrm{PREM}_{t}+a_{3 p} d_{p t-1}+\epsilon_{p t},
$$

where $d_{p t-1}$ is the dividend yield for portfolio $p$. The estimates, along with their $t$-statistics, are shown in part A of table $2 .^{7}$

The coefficients and $t$-statistics in the above regressions appear to exhibit a distinct pattern that is related to dividend yield, and this pattern appears within each quintile of firm size. Portfolios 1-4 constitute the smallest size quintile, portfolios 5-8 make up the next larger size quintile, and so forth. Within a size quintile, dividend yield is increasing with the portfolio number. Thus, the highest-yield portfolios for each size quintile (in increasing order of firm size) are portfolios 4 ,

7. The $t$-statistics are based on heteroscedasticity-consistent estimates of standard errors (White 1980, and Hsieh 1983). 
$8,12,16$, and 20 . Note that for these highest-yield portfolios, the estimated $a_{3 p}$ 's, and especially their $t$-statistics, tend to be greater than those for the other portfolios. In contrast, the estimated $a_{3 p}$ 's for the lowest-yield portfolios $(1,5,9,13$, and 17) are, except for the smallest size quintile (portfolio 1), negative. It appears that dividend yield is related positively over time to expected returns for high-yield firms and negatively to expected returns for low-yield firms.

One possible explanation for the above results is that the risk measures $\beta_{p(m)}$ and $\delta_{p}$ change through time in a manner related to dividend yield. In other words, the assumption of constant risk measures causes the estimated market-adjusted returns to contain an error that is related to dividend yield ${ }^{8}$ In order to investigate this possibility, the crossproduct terms $d_{p t} \cdot \mathrm{RVW}_{t}$ and $d_{p t} \cdot \mathrm{PREM}_{t}$ are included as additional independent variables in the regression in (3). If the changes in $\beta_{p(m)}$ and $\delta_{p}$ are linearly related to the change in $d_{p t}$, this relation will be reflected in the coefficients on the cross-product terms. The estimated coefficients and $t$-statistics for these regressions are reported in part B of table 2. The chi-square statistics for the slope coefficients corresponding to the two cross-product terms strongly reject the null hypothesis that the coefficients are zero. Furthermore, the abovementioned pattern in the $t$-statistics for the dividend-yield slope coefficient is no longer observable and the chi-square statistics for their joint significance has dropped substantially to 15.0 with a $p$-value of 0.78 . Given the significance of the cross-product terms in these regressions, we conclude that changes in $\beta_{p}$ and $\delta_{p}$ are indeed related to dividend yield. These results reinforce the point that one should be cautious in interpreting the coefficient corresponding to dividend yield in any empirical design where the risk measures or the risk premiums are assumed to be constant over time.

In the following sections, we examine the dividend yield effect in experimental designs that allow the risk measures to be constant as well as stochastic. Each design imposes a slightly different set of structures. Fortunately, among the experiments that we have conducted, the results are rather insensitive to the particular design. When we use the CAPM (eq. [2]) to adjust for risk, we observe a positive relation between yield and expected return. When we use the two-factor model (eq. [1]) for the risk adjustment, there appears to be no reliable relation between expected return and yield. The evidence suggests that many of the observed positive relations between yield and return may well be due to the inadequacy of the asset-pricing equation previously employed.

8. This problem is discussed in the context of models with a single risk measure by Miller and Scholes (1982) and Hess (1983). 
TABLE 2 Time Series Regressions, 1943-78*

\begin{tabular}{|c|c|c|c|c|c|c|}
\hline \multirow[b]{2}{*}{ Portfolio } & \multicolumn{3}{|c|}{ Part A: Regression (i) } & \multicolumn{3}{|c|}{ Part B: Regression (ii) } \\
\hline & $\mathrm{RVW}_{t}$ & $\mathrm{PREM}_{t}$ & $d_{p t-1}$ & $d_{p t-1} \cdot \mathrm{RVW}_{t}$ & $d_{p t-1} \cdot \mathrm{PREM}_{t}$ & $d_{p t-1}$ \\
\hline & \multicolumn{6}{|c|}{ Coefficient Estimates } \\
\hline 1 & 1.2789 & .5750 & .0282 & -5.6851 & 19.0777 & -.0470 \\
\hline 2 & 1.0749 & .6000 & .0446 & 3.7915 & 9.5386 & -.0475 \\
\hline 3 & 1.0273 & .4318 & .0277 & 3.6804 & 8.3718 & -.0654 \\
\hline 4 & .8780 & .4741 & .1050 & 5.0749 & 6.4744 & -.0027 \\
\hline 5 & 1.2903 & .3519 & -.1447 & -5.0528 & 17.1311 & -.2112 \\
\hline 6 & 1.1647 & .2737 & -.0913 & .0550 & 2.3444 & -.1045 \\
\hline 7 & 1.0483 & .3704 & -.0045 & 3.5247 & 6.6376 & -.0812 \\
\hline 8 & .9202 & .3403 & .0519 & 3.9237 & 7.0383 & -.0410 \\
\hline 9 & 1.3411 & .1269 & -.0795 & -3.9551 & 6.3523 & -.0863 \\
\hline 10 & 1.0862 & .2229 & .0156 & -.0061 & 3.9543 & -.0080 \\
\hline 11 & 1.0200 & .2041 & .0201 & 2.2012 & 4.9454 & -.0339 \\
\hline 12 & .9000 & .2593 & .0775 & 3.1846 & 5.0927 & .0110 \\
\hline 13 & 1.2493 & .0098 & -.1229 & -6.6042 & .9487 & -.0628 \\
\hline 14 & 1.0802 & .0319 & .0062 & -2.1232 & 2.8080 & .0099 \\
\hline 15 & 1.0464 & .0799 & .0221 & 1.5457 & 5.4217 & -.0290 \\
\hline 16 & .9431 & .1921 & .0336 & 2.5578 & 4.0239 & -.0269 \\
\hline 17 & 1.1123 & -.0868 & -.1215 & -5.1211 & -7.4096 & -.0386 \\
\hline 18 & 1.0192 & -.0876 & .0835 & -3.3145 & 6.0716 & .0806 \\
\hline 19 & .9718 & .0018 & .0376 & 2.6442 & 4.1191 & -.0151 \\
\hline \multirow[t]{2}{*}{20} & 9077 & .1979 & .0847 & 2.8838 & 4.0151 & .0245 \\
\hline & \multicolumn{6}{|c|}{$t$-Statistics (vs. Zero) $\dagger$} \\
\hline 1 & 15.956 & 4.581 & .113 & -.682 & 1.295 & -.194 \\
\hline 2 & 14.706 & 6.095 & .335 & .854 & 1.553 & -.399 \\
\hline 3 & 15.723 & 4.707 & .320 & 1.211 & 1.865 & -.823 \\
\hline 4 & 13.592 & 5.462 & 1.794 & 2.687 & 2.411 & -.054 \\
\hline 5 & 21.242 & 4.188 & -.893 & -.888 & 2.394 & -1.517 \\
\hline 6 & 21.426 & 3.835 & -.892 & .016 & .534 & -1.078 \\
\hline 7 & 19.635 & 5.788 & -.061 & 1.277 & 2.324 & -1.206 \\
\hline 8 & 21.068 & 4.937 & 1.131 & 2.930 & 3.358 & -1.061 \\
\hline 9 & 31.093 & 2.195 & -.781 & -1.011 & 1.424 & -.883 \\
\hline 10 & 25.437 & 3.924 & .200 & -.002 & 1.165 & -.108 \\
\hline 11 & 26.488 & 4.121 & .355 & 1.172 & 2.166 & -.639 \\
\hline 12 & 20.874 & 4.549 & 1.970 & 2.634 & 3.077 & .321 \\
\hline 13 & 49.498 & .183 & -1.560 & -3.010 & .267 & -.816 \\
\hline 14 & 39.208 & .755 & .112 & -1.244 & 1.084 & .175 \\
\hline 15 & 36.468 & 1.759 & .479 & .960 & 2.174 & -.606 \\
\hline 16 & 23.879 & 3.281 & .910 & 2.458 & 2.405 & -.813 \\
\hline 17 & 46.450 & -2.331 & -2.021 & -2.823 & -3.000 & -.731 \\
\hline 18 & 51.607 & -2.505 & 2.041 & -2.430 & 3.017 & 1.970 \\
\hline 19 & 52.468 & .050 & 1.010 & 2.529 & 2.481 & -.417 \\
\hline 20 & 25.704 & 3.489 & 2.251 & 2.113 & 2.188 & .669 \\
\hline
\end{tabular}


TABLE 2 (Continued)

\begin{tabular}{|c|c|c|c|c|c|c|}
\hline \multirow[b]{2}{*}{ Portfolio } & \multicolumn{3}{|c|}{ Part A: Regression (i) } & \multicolumn{3}{|c|}{ Part B: Regression (ii) } \\
\hline & $\mathrm{RVW}_{t}$ & PREM $_{t}$ & $d_{p t-1}$ & $d_{p t-1} \cdot \mathrm{RVW}_{t}$ & $d_{p t-1} \cdot \mathrm{PREM}_{t}$ & $d_{p t-1}$ \\
\hline & \multicolumn{6}{|c|}{ Chi-Square Statistic ( $p$-Value in Parentheses) $\ddagger$} \\
\hline & $\begin{array}{r}19,515 \\
(.00)\end{array}$ & $\begin{array}{r}296.5 \\
(.00)\end{array}$ & $\begin{array}{l}28.8 \\
(.09)\end{array}$ & $\begin{array}{l}72.5 \\
(.00)\end{array}$ & $\begin{array}{l}94.4 \\
(.00)\end{array}$ & $\begin{array}{c}15.0 \\
(.78)\end{array}$ \\
\hline
\end{tabular}

* $R_{p t}$ is the monthly excess return on portfolio $p, \mathrm{RVW}_{t}$ is the excess return on the value-weighted NYSE, PREM, is the difference in returns between below-BAA-rated bonds and U.S. government bonds, and $d_{p t-1}$ is the average annual dividend yield for portfolio $p$.

$\dagger$ Based on heteroscedasticity-consistent standard errors (White 1980; and Hsieh 1983).

$¥$ The test statistic is asymptotically distributed as $\chi^{2}$ with 20 degrees of freedom under the null hypothesis that all of the coefficients in the column are equal to zero.

\section{Tests Using the Time-Series (SUR) Approach}

We now turn to direct tests for the presence of dividend-yield effects in expected asset returns. This section uses a system of time-series regressions as in (1) to impose restrictions implied by a pricing specification that expected returns are linearly related to the two risk measures. Given these pricing restrictions, we then test whether dividend yield is linearly related to risk-adjusted expected returns. In the case of a pricing model with risk measures $\beta_{p(m)}$ and $\delta_{p}$, expected returns are specified as

$$
E\left(R_{p t}\right)=\lambda_{0}+\lambda_{1} \beta_{p(m)}+\lambda_{2} \delta_{p}+\lambda_{3} d_{p t-1} .
$$

The main hypothesis of interest is whether $\lambda_{3}=0$. Combining the pricing restriction in (4) with the system of time-series regressions in (1) yields a set of restricted Seemingly Unrelated Regressions (SUR) of the form

$R_{p t}=\lambda_{0}+\beta_{p(m)}\left(\mathrm{RVW}_{t}+\lambda_{1}^{*}\right)+\delta_{p}\left(\mathrm{PREM}_{t}+\lambda_{2}^{*}\right)+\lambda_{3} d_{p t-1}+\epsilon_{p t}$,

where

$$
\lambda_{1}^{*}=\lambda_{1}-E\left(\mathrm{RVW}_{t}\right) \text { and } \lambda_{2}^{*}=\lambda_{2}-E\left(\mathrm{PREM}_{t}\right) .
$$

We estimate the system of regressions in (5) for the 20 positive-yield portfolios. Table 3 reports results for this two-factor model where both $\beta_{p(m)}$ and $\delta_{p}$ are risk measures. All of the point estimates of $\lambda_{3}$ are positive, but inferences about whether $\lambda_{3}=0$ vary. The coefficient on dividend yield is more than 2 standard errors above zero in the second subperiod but not in the first subperiod. The overall-period estimate of $\lambda_{3}$ is only about 1 standard error above zero. This pattern mirrors that in the chi-square statistic for the test of whether the coefficients for the yield variable in equation (3) are jointly equal to zero. That statistic, distributed $\chi^{2}(20)$ under the null hypothesis, is large in the second subperiod $\left(\chi^{2}=66.6, p\right.$-value $\left.=0.000\right)$ but not in the first subperiod 
TABLE 3 Nonlinear Seemingly Unrelated Regression Estimation with Two Factors Plus Dividend Yield; Portfolios Sorted by Size and Yield (Standard Errors in Parentheses)*

\begin{tabular}{|c|c|c|c|c|}
\hline & $\lambda_{0}+\lambda_{1} \beta_{p}$ & $\delta_{p}+\lambda_{3} d$ & & (ii) \\
\hline Period & $\hat{\lambda}_{0}$ & $\hat{\lambda}_{1}$ & $\hat{\lambda}_{2}$ & $\hat{\lambda}_{3}$ \\
\hline January 1943- & & & & \\
\hline December 1978 & $\begin{array}{c}.4971 \\
(.3243)\end{array}$ & $\begin{array}{c}.4013 \\
(.3370)\end{array}$ & $\begin{array}{l}1.0254 \\
(.2671)\end{array}$ & $\begin{array}{r}.1723 \\
(.1652)\end{array}$ \\
\hline January 1943- & & & & \\
\hline December 1960 & $\begin{array}{l}1.6030 \\
(.4446)\end{array}$ & $\begin{array}{r}-.3594 \\
(.4535)\end{array}$ & $\begin{array}{c}.5828 \\
(.2606)\end{array}$ & $\begin{array}{r}.1075 \\
(.1884)\end{array}$ \\
\hline January 1961- & & & & \\
\hline December 1978 & $\begin{array}{c}-.6498 \\
(.4819)\end{array}$ & $\begin{array}{l}1.0402 \\
(.4860)\end{array}$ & $\begin{array}{l}1.4247 \\
(.4056)\end{array}$ & $\begin{array}{r}.8416 \\
(.3703)\end{array}$ \\
\hline
\end{tabular}

Note. - The system of equations in (i) is estimated jointly across 20 portfolios of positive-yield firms. The variables are defined as follows:

$\boldsymbol{R}_{p t}=$ return on portfolio $p$, equally weighted, in excess of the return on a 1-month Treasury bill;

$\mathrm{RVW}_{t}=$ excess return on the value-weighted portfolio of all stocks on the NYSE;

PREM $_{t}=$ return on below-BAA bonds minus the return on long-term U.S. government bonds; and

$d_{p t-1}=$ the equally weighted average annual dividend yield of stocks in portfolio $p$.

The estimate of $\lambda_{1}$ in (ii) equals $\hat{\lambda}_{1}^{*}$ plus the mean of RVW, and the asymptotic variance of $\hat{\lambda}_{1}$ equals the sum of the variances of those two quantities. A similar procedure is used for $\hat{\lambda}_{2}$.

* The numbers corresponding to the yield variable are multiplied by 12 , and the other numbers are multiplied by 100 in the table.

$\left(\chi^{2}=20.1, p\right.$-value $\left.=0.452\right)$, and it is marginal for the overall period $\left(\chi^{2}=28.8, p\right.$-value $\left.=0.092\right)$.

The evidence presented in the previous section suggests that the dividend-yield variable in the SUR approach may be proxying for changes over time in risk or risk premiums. In the next three sections, we examine the dividend-yield effect with other designs that allow the risk measures and the risk premiums to change over time and, in some cases, allow us to model the stochastic risk measures and the risk premiums more explicitly.

\section{The Cross-sectional (Two-Step) Approach}

In this section, we rerun the tests using the two-step Fama-Macbeth methodology. In the first step, we estimate each year the risk measures $\beta_{p(m)}$ and $\delta_{p}$ for each of the 20 portfolios using monthly returns over the previous 5 years. In the second step, we regress cross-sectionally month by month the portfolio returns on the estimated portfolio multiple risk measures and the dividend yields. This process is repeated for 
TABLE 4 Fama-MacBeth Estimation with Two Factors Plus Dividend Yield;

\begin{tabular}{|c|c|c|c|c|}
\hline & \multicolumn{3}{|c|}{$\begin{array}{l}R_{p t}=\lambda_{0}^{\prime}+\beta_{p(m)}\left(\mathrm{RVW}_{t}\right)+\delta_{p}\left(\mathrm{PREM}_{t}\right)+\epsilon_{p t} \\
E\left(R_{p t}\right)=\lambda_{0}+\lambda_{1} \hat{\beta}_{p(m)}+\lambda_{2} \hat{\delta}_{p}+\lambda_{3} d_{p t-1}\end{array}$} & \multirow{2}{*}{$\begin{array}{r}\text { heses)* } \\
\text { (i) } \\
\text { (ii) } \\
\hat{\lambda}_{3}\end{array}$} \\
\hline Period & $\hat{\lambda}_{0}$ & $\hat{\lambda}_{1}$ & $\hat{\lambda}_{2}$ & \\
\hline \multicolumn{5}{|l|}{ January 1943- } \\
\hline December 1978 & $\begin{array}{c}.7997 \\
(.3336)\end{array}$ & $\begin{array}{c}.1072 \\
(.2746)\end{array}$ & $\begin{array}{c}.7113 \\
(.2506)\end{array}$ & $\begin{array}{c}.0710 \\
(.3387)\end{array}$ \\
\hline \multicolumn{5}{|l|}{ January 1943- } \\
\hline December 1960 & $\begin{array}{l}1.0537 \\
(.3597)\end{array}$ & $\begin{array}{c}.2360 \\
(.3482)\end{array}$ & $\begin{array}{c}.1838 \\
(.2608)\end{array}$ & $\begin{array}{r}-.2434 \\
(.2515)\end{array}$ \\
\hline \multicolumn{5}{|l|}{ January 1961- } \\
\hline December 1978 & $\begin{array}{c}.5457 \\
(.5634)\end{array}$ & $\begin{array}{r}-.0215 \\
(.4261)\end{array}$ & $\begin{array}{l}1.2388 \\
(.4263)\end{array}$ & $\begin{array}{l}.3855 \\
(.6299)\end{array}$ \\
\hline
\end{tabular}

NotE.-Equation (i) for the 20 portfolios of positive-yield firms is estimated over the previous 60 months. The estimates, updated once a year, are used in the second-step regression (ii). The variables are defined as follows:

$R_{p t}=$ return on portfolio $p$, equally weighted, in excess of the return on a 1-month Treasury bill;

$\mathrm{RVW}_{t}=$ excess return on the value-weighted portfolio of all stocks on the NYSE;

$\mathrm{PREM}_{t}=$ return on below-BAA bonds minus the return on long-term U.S. government bonds; and

$d_{p t-1}=$ the equally weighted average annual dividend yield of stocks in portfolio $p$.

* The numbers corresponding to the yield variable are multiplied by 12 , and the other numbers are multiplied by 100 in the table.

each year from 1943 to 1978 , and the estimated risk measures and the dividend yields are updated every year. The cross-sectional regressions generate a monthly series of slope coefficients for each (multiple) risk measure and the dividend yield variable. If there is no crosssectional relation between return and dividend yield, then the slope coefficient for the yield variable should be statistically indistinguishable from zero.

The Fama-MacBeth approach allows the risk premium to change every month and may also reduce the contaminating effects of changing risk measures discussed earlier, especially if the changes in risk measures arise mainly from changing portfolio composition. Even if changes in betas occur for other reasons (still associated with dividend yield), the updating of the beta estimates through time should attenuate the contaminating effects.

The second-stage regression results are reported in table 4 . The coefficient corresponding to the dividend-yield variable is never reliably different from zero. The point estimate for the yield variable fluctuates substantially from the early period $(-.24)$ to the later period $(+.38)$. Overall, this estimate of the tax penalty is so imprecise relative to the 
estimated standard error that we cannot reject the null hypothesis of no penalty on dividends. ${ }^{9}$

\section{An Unconditional (Two-Step) Approach}

Instead of updating the beta estimates over time using a 5-year window, we can model the stochastic risk measures and the stochastic risk premiums. One such approach is used in Chan and Chen (1988). They assume that the conditional risk measure, $\tilde{\beta}_{p k t-1}$, the risk exposure of portfolio $p$ to factor $k$ known at the end of period $t-1$, has a stationary distribution with mean $\bar{\beta}_{p k}$ and that $\bar{\beta}_{k}$ exists and is the cross-sectional mean of the $\bar{\beta}_{p k}$ 's. Furthermore, $\tilde{\beta}_{p k t-1}$ is assumed to satisfy the separability condition

$$
\tilde{\beta}_{p k t-1}=\bar{\beta}_{p k}+\tilde{\theta}_{k t-1}\left(\bar{\beta}_{p k}-\overline{\bar{\beta}}_{k}\right)+\tilde{\eta}_{p k t-1},
$$

which is linear in $\bar{\beta}_{p k}$, where $\tilde{\theta}_{k t-1}$ is a state variable with zero mean that affects risk measures across all securities, and $\tilde{\eta}_{p k t-1}$ is a random noise term independent of all other quantities. The conditional factor risk premium is allowed to be stochastic over time. This linear structure preserves a linear relation between the unconditional expected return and the unconditional (multiple) risk measures. Consequently, we can test equation (4) with unconditional parameters estimated using long time periods.

The main advantage of this approach is that we need not specify a complete set of state variables that affect risk measures and risk premiums. The disadvantage is that assumption (6) is not directly testable. An implication of (6) is that the cross-sectional correlations of the unconditional risk measures estimated over nonoverlapping periods should be high. In our case, the correlations of the estimated unconditional risk measures between the first and second subperiods are about .8. This suggests that (6) may be a reasonable working approximation for our problem, although the correlations are not as high as those corresponding to size-ranked portfolios reported in Chan and Chen (1988).

With this approach, we estimate the unconditional risk measures in time-series regressions in the first step, always using all of the data points except for the 12 months of the year in which the second-step regressions are run. In the second-step cross-sectional regressions, we

9. Using $\log$ (size) as a size proxy and the Fama-MacBeth approach, Keim (1983) finds that the yield coefficient, though insignificant overall, is reliably positive in January. We also observe a reliably positive yield coefficient $(t=3.54)$ in January for the single-factor (CAPM) model. However, the January yield coefficient, like the overall yield coefficient, becomes statistically indistinguishable from zero $(t=1.10)$ when PREM is included as a second factor to control for risk. 
TABLE 5 Unconditional Estimation with Two Factors Plus Dividend Yield; Portfolios Sorted by Size and Yield (Standard Errors in Parentheses)*

$R_{p t}=\lambda_{0}^{\prime}+\beta_{p(m)}^{u}\left(\mathrm{RVW}_{t}\right)+\delta_{p}^{u}\left(\mathrm{PREM}_{t}\right)+\epsilon_{p t}$

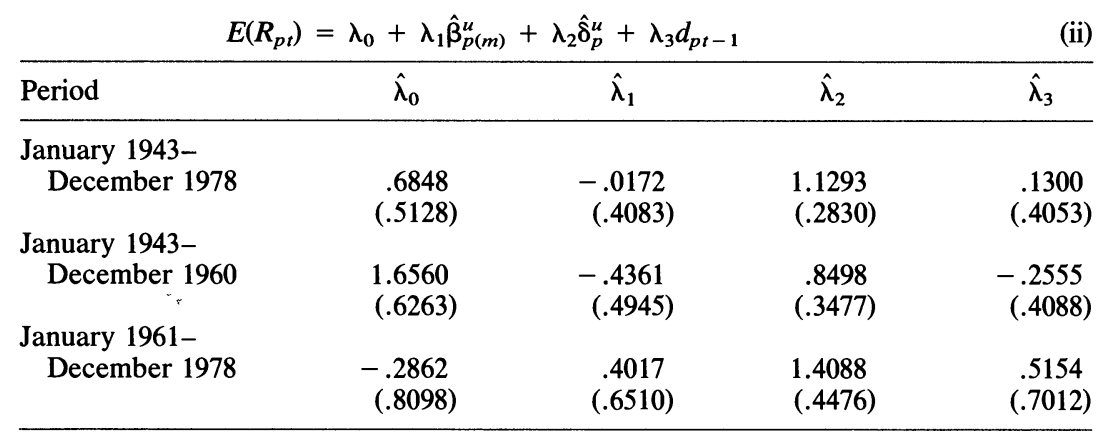

NoTE.-For every year $t$ in the period 1943-78, equation (i) for the 20 positive yield portfolios is estimated over the entire time period excluding the 12 months in year $t$. The estimated parameters are used in the second-step regression (ii) for year $t$. The variables are defined as follows:

$\boldsymbol{R}_{p t}=$ return on portfolio $p$, equally weighted, in excess of the return on a 1-month Treasury bill;

$\mathrm{RVW}_{t}=$ excess return on the value-weighted portfolio of all stocks on the NYSE;

PREM $_{t}=$ return on below-BAA bonds minus the return on long-term U.S. government bonds; and

$d_{p t-1}=$ the equally weighted average annual dividend yield of stocks in portfolio $p$.

* The numbers corresponding to the yield variable are multiplied by 12 , and the other numbers are multiplied by 100 in the table.

regress realized returns of the 20 portfolios on the estimated risk measures and the dividend yield.

The second-step results are reported in table 5. As in the FamaMacBeth approach, the coefficient corresponding to the dividend-yield variable is not reliably different from zero. The point estimates for the yield variable again fluctuate substantially from the early period to the later period, and the overall estimate of the tax penalty is again so imprecise that we cannot reject the null hypothesis of no penalty on cash dividends.

\section{An Approach that Models Dividend-related Parameter Changes}

Finally, we pursue an approach in which risk measures and risk premiums are modeled explicitly as functions of dividend yields. The return-generating equations and the pricing equations are given by

$$
R_{p t}=E_{t-1}\left(R_{p, t}\right)+\beta_{p(m), t-1} \Delta_{m, t}+\delta_{p, t-1} \Delta_{\mathrm{PREM}, t}+u_{p, t}
$$

and

$$
E_{t-1}\left(R_{p, t}\right)=\lambda_{0}+\beta_{p(m), t-1} \lambda_{1 t-1}+\delta_{p, t-1} \lambda_{2 t-1}+\lambda_{3} d_{p t-1},
$$


where

$$
\begin{aligned}
\Delta_{m, t} & =\mathrm{RVW}_{t}-E_{t-1}\left(\mathrm{RVW}_{t}\right), \\
\Delta_{\mathrm{PREM}, t} & =\mathrm{PREM}_{t}-E_{t-1}\left(\mathrm{PREM}_{t}\right), \\
\lambda_{1-1} & =E_{t-1}\left(\mathrm{RVW}_{t}\right)+\lambda_{1}^{*},
\end{aligned}
$$

and

$$
\lambda_{2 t-1}=E_{t-1}\left(\operatorname{PREM}_{t}\right)+\lambda_{2}^{*} .
$$

Risk premiums are specified as linear functions of the overall crosssectional average dividend yield, $\bar{d}_{t-1}$ :

$$
\begin{aligned}
E_{t-1}\left(\mathrm{RVW}_{t}\right) & =\theta_{0}+\theta_{1} \bar{d}_{t-1}, \\
E_{t-1}\left(\mathrm{PREM}_{t}\right) & =\alpha_{0}+\alpha_{1} \bar{d}_{t-1} .
\end{aligned}
$$

A portfolio's risk measures are specified as linear functions of the average annual dividend yield of the stocks in the portfolio, $d_{p, t-1}$ :

$$
\begin{aligned}
\beta_{p(m), t-1} & =\beta_{0 p}+\beta_{1 p} d_{p, t-1}, \\
\delta_{p, t-1} & =\delta_{0 p}+\delta_{1 p} d_{p, t-1} .
\end{aligned}
$$

Recall that this linear specification was investigated earlier in part B of table 2 .

The Generalized Method of Moments (Hansen 1982) is used to estimate the parameters $\lambda_{0}, \lambda_{1}^{*}, \lambda_{2}^{*}, \lambda_{3}, \theta_{0}, \theta_{1}, \alpha_{0}, \alpha_{1}, \beta_{0}, \beta_{1}, \underline{\delta}_{0}, \underline{\delta}_{1}$. The orthogonality conditions we select for the estimation of the model are

$$
\begin{aligned}
E\left(u_{p, t} \cdot \underline{X}_{p, t-1}\right) & =0, \quad p=1, \ldots, n, \\
E\left(\Delta_{m, t} \cdot \underline{D}_{t-1}\right) & =0, \\
E\left(\Delta_{\mathrm{PREM}, t} \cdot \underline{D}_{t-1}\right) & =0, \\
E\left(\epsilon_{p, t} \cdot \underline{D}_{p, t-1}\right) & =0, \quad p=1, \ldots, n, \\
E\left(\eta_{p, t} \cdot \underline{D}_{p, t-1}\right) & =0, \quad p=1, \ldots, n,
\end{aligned}
$$

where $\underline{\epsilon}_{t}=\Delta_{m, t} \underline{u}_{t}, \underline{\eta}_{t}=\Delta_{\mathrm{PREM}, t} \underline{u}_{t}, \underline{X}_{p, t-1}^{\prime}=\left(1 d_{p t-1}\right), \underline{D}_{t-1}^{\prime}=\left(1 \bar{d}_{t-1}\right)$, $\underline{D}_{p, t-1}^{\prime}=\left(1 \bar{d}_{t-1} d_{p t-1}\right)$, and $\underline{u}_{t}^{\prime}=\left(u_{1, t}, \ldots, u_{n, t}\right)$. If $n$ denotes the number of portfolios, then there are $8 n+4$ orthogonality conditions and $4 n+8$ parameters, producing $4 n-4$ overidentifying restrictions. In this case, since $n=20$, there are 76 overidentifying restrictions.

Selected parameter estimates, along with their asymptotic standard errors, are reported in table 6. The estimates of $\theta_{1}$ and $\alpha_{1}$, relative to their standard errors, allow us to infer that the risk premiums for both $\beta_{p(m)}$ and $\delta_{p}$ are changing as functions of the lagged average dividend yield. ${ }^{10}$ The estimated $\beta_{1 p}$ 's and $\delta_{1 p}$ 's indicate that risk measures are

10. A positive relation between the market-risk premium and dividend yield has been reported previously by Rozeff (1984) and Fama and French (1988). 
TABLE 6 Generalized Method of Moments Estimation with Two Factors Plus Dividend Yield, January 1943-December 1978; Portfolios Sorted by Size and Yield (Standard Errors in Parentheses)

\begin{tabular}{|c|c|}
\hline \multicolumn{2}{|c|}{$\begin{array}{rlrl}R_{p t}=\lambda_{0}+\beta_{p(m), t-1}\left(\lambda_{1 t-1}+\Delta_{m t}\right)+\delta_{p, t-1}\left(\lambda_{2 t-1}+\Delta_{\text {PREM }, t}\right)+\lambda_{3} d_{p t-1}+u_{p t} \\
\Delta_{m, t} & =\mathrm{RVW}_{t}-E_{t-1}\left(\mathrm{RVW}_{t}\right), & \Delta_{\mathrm{PREM}, t} & =\mathrm{PREM}_{t}-\mathrm{E}_{t-1}\left(\mathrm{PREM}_{t}\right) \\
\mathrm{E}_{t-1}\left(\mathrm{RVW}_{t}\right) & =\theta_{0}+\theta_{1} \bar{d}_{t-1}, & E_{t-1}\left(\mathrm{PREM}_{t}\right) & =\alpha_{0}+\alpha_{1} \bar{d}_{t-1}, \\
\beta_{p(m), t-1} & =\beta_{0 p}+\beta_{1 p} d_{p, t-1}, & \delta_{p, t-1} & =\delta_{0 p}+\delta_{1 p} d_{p, t-1}, \\
\lambda_{1 t-1} & =E_{t-1}\left(\mathrm{RVW}_{t}\right)+\lambda_{1}^{*}, & \lambda_{2 t, 1} & =E_{t-1}\left(\mathrm{PREM}_{t}\right)+\lambda_{2}^{*} .\end{array}$} \\
\hline \multicolumn{2}{|c|}{$\begin{aligned} \lambda_{0} & =.8384(.2883) \\
E\left(\lambda_{11}\right) & =-.1167(.3075) \\
E\left(\lambda_{2 t}\right) & =.7594(.1745) \\
\lambda_{3} & =.0200(.1549)\end{aligned}$} \\
\hline \multicolumn{2}{|c|}{$\begin{array}{c}\chi_{(76)}^{2}=87.4103 \\
(p \text {-value }=.1746)\end{array}$} \\
\hline$\theta_{1}=.4022(.0830)$ & $\alpha_{1}=.2467(.0412)$ \\
\hline $\begin{array}{l}\beta_{1,1}=-21.07(6.09) \\
\beta_{1,4}=3.13(1.21) \\
\beta_{1,5}=-19.20(4.61) \\
\beta_{1,8}=.27(0.97) \\
\beta_{1,9}=-11.15(2.34) \\
\beta_{1,12}=1.63(.88) \\
\beta_{1,13}=-10.35(2.04) \\
\beta_{1,16}=.87(1.11) \\
\beta_{1,17}=-4.73(1.26) \\
\beta_{1,20}=2.94(1.28)\end{array}$ & $\begin{array}{l}\delta_{1,1}=66.12(10.73) \\
\delta_{1,4}=5.59(1.98) \\
\delta_{1,5}=47.19(7.81) \\
\delta_{1,8}=12.21(1.45) \\
\delta_{1,9}=-2.13(3.74) \\
\delta_{1,12}=3.58(1.29) \\
\delta_{1,13}=-16.93(4.91) \\
\delta_{1,16}=12.79(2.30) \\
\delta_{1,17}=-16.69(2.80) \\
\delta_{1,20}=-7.51(2.72)\end{array}$ \\
\hline
\end{tabular}

Note.-The variables are defined as follows:

$\boldsymbol{R}_{p t}=$ return on portfolio $p$ in excess of the return on a 1-month Treasury bill;

$\mathrm{RVW}_{t}=$ excess return on the value-weighted portfolio of all stocks on the NYSE;

PREM $_{t}=$ return on below-BAA bonds minus the return on long-term U.S. government bonds;

$d_{\underline{p} t-1}=$ the equally weighted average annual dividend yield of stocks in portfolio $p$; and

$\bar{d}_{t-1}=$ the average $d_{p t-1}$ across $p$.

The numbers corresponding to $\lambda_{0}, E\left(\lambda_{1}\right)$, and $E\left(\lambda_{2}\right)$ in the table are multiplied by 100 , and the numbers corresponding to $\lambda_{3}$ are multiplied by 12 . The $\chi^{2}$ statistic provides a test of the model's 76 overidentifying restrictions.

also changing as a function of the lagged dividend yields, and the patterns across high- and low-yield portfolios are similar to those found for the cross-product terms in part B of table 2. The estimate of $\lambda_{3}$, the penalty for cash dividends, is 0.02 with an asymptotic standard error of 0.15 , which indicates that the coefficient is not reliably different from zero. The chi-square statistic indicates that the model's overidentifying restrictions are not rejected by the data.

\section{Conclusions}

This study addresses the question of whether there is a tax penalty associated with cash dividends. In other words, does the relative price between cash dividend and capital gain deviate from unity over a long 
period of time? We investigate this problem by drawing inferences from the risk-adjusted returns of firms with diverse long-run dividend yields-the presence of a tax penalty is equivalent to the observation of higher (expected) total returns (capital gains + dividends) from high-yield firms after adjusting for risk.

Before examining the relation between risk-adjusted returns and dividend yields, we investigate some of the joint time-series properties of returns, dividend yields, and risk measures. We find that returns and dividend yields are related over time and that at least part of this relation can be attributed to dividend-related changes in risk measures. These time-series relations considerably complicate the interpretations of any effect induced by taxes.

We perform a series of tests to detect a tax-induced dividend-yield effect. The methodologies include: (i) a Seemingly Unrelated Regressions approach, (ii) a Fama-MacBeth approach, (iii) an unconditional approach suggested by Chan and Chen (1988) and (iv) an approach that explicitly models dividend-related changes in risk measures and risk premiums. In each case, if the value-weighted market beta is the only risk-adjustment, the estimated dividend coefficient is reliably positive. However, when we include a second risk measure PREM, motivated by the changing investment opportunity set, the dividend coefficient is generally not statistically distinguishable from zero.

Given the above evidence, one might be tempted to conclude that, given the appropriate pricing model and the appropriate empirical design that controls for effects induced by dividend-related changes in risk premiums and risk measures, there appears to be no tax penalty on cash dividends. We believe, however, that such a conclusion is premature. Based on theoretical studies about the information content of dividends and empirical studies (including this one) of the relation between expected returns and dividend yield, we conclude that the dividend-yield measure is likely to be correlated with many other economic phenomena. Unless we are confident that all of the other effects are accounted for and that the results are robust to minor changes in test methodologies, we would hesitate to make any definitive inferences regarding the tax-induced effect of dividends. If, indeed, there is a tax-induced penalty on cash dividends, its presence in the data is likely to be intertwined with other dividend-related effects. At this point, the data do not clearly indicate a penalty on cash dividends.

\section{References}

Black, F., and Scholes, M. 1974. The effects of dividend yields and dividend policy on common stock prices and returns. Journal of Financial Economics 1:1-22.

Blume, M. 1980. Stock returns and dividend yields: Some more evidence. Review of Economics and Statistics 62:567-77. 
Brennan, M. J. 1970. Taxes, market valuation, and corporate financial policy. National Tax Journal 23:417-27.

Chan, K. C.; Chen, N.; and Hsieh, D. 1985. An exploratory investigation of the firm size effect. Journal of Financial Economics 14:451-71.

Chan, K. C., and Chen, N. 1988. An unconditional asset pricing test and the role of firm size as an instrumental variable for risk. Journal of Finance 43:309-25.

Chen, N.; Roll, R.; and Ross, S. 1986. Economic forces and the stock market. Journal of Business 59:383-403.

Cox, J.; Ingersoll, J.; and Ross, S. 1985. An intertemporal general equilibrium model of asset prices. Econometrica 53:363-84.

Eades, K.; Hess, P.; and Kim, E. 1984. On interpreting security returns during the exdividend period. Journal of Financial Economics 13:3-34.

Elton, E., and Gruber, M. 1970. Marginal stockholder tax rates and the clientele effect. Review of Economics and Statistics 52:68-74.

Elton, E.; Gruber, M.; and Rentzler, J. 1984. The ex-dividend day behavior of stock prices: A re-examination of the clientele effect: A comment. Journal of Finance 39:551-56.

Fama, E. F., and MacBeth, J. D. 1973. Risk, return, and equilibrium: Empirical tests. Journal of Political Economy 81:607-36.

Fama, E. F., and French, K. R. 1988. Dividend yields and expected stock returns. Journal of Financial Economics 22:3-25.

Green, J. 1980. Taxation and the ex-dividend behavior of common stock prices. Working Paper no. 496. Boston: National Bureau of Economic Research.

Grundy, B. 1985. Trading volume and stock returns around ex-dividend dates. Mimeographed. Chicago: University of Chicago.

Hansen, L. P. 1982. Large sample properties of generalized method of moments estimators. Econometrica 50:1029-54.

Hess, P. 1983. Tests for tax effects in the pricing of financial assets. Journal of Business 56:537-54.

Hsieh, D. 1983. A heteroscedasticity-consistent covariance matrix estimator for time series regressions. Journal of Econometrics 22:281-90.

Kalay, A. 1982. The ex-dividend day behavior of stock prices: A reexamination of the clientele effect. Journal of Finance 37:1059-70.

Kalay, A. 1984. The ex-dividend day behavior of stock prices: A reexamination of the clientele effect: A reply. Journal of Finance 39:557-61.

Keim, D. B. 1983. The interrelation between dividend yields, equity values and stock returns: Implications of abnormal January returns. Ph.D. dissertation, University of Chicago.

Keim, D. B. 1985. Dividend yields and stock returns: Implications of abnormal January returns. Journal of Financial Economics 14:473-89.

Keim, D. B., and Stambaugh, R. F. 1986. Predicting returns in the stock and bond markets. Journal of Financial Economics 17:357-90.

Lakonishok, J., and Vermaelen, T. 1983. Tax reform and ex-dividend behavior. Journal of Finance 38:1157-79.

Lakonishok, J., and Vermaelen, T. 1986. Tax-induced trading around ex-dividend dates. Journal of Financial Economics 16:287-319.

Litzenberger, R. H., and Ramaswamy, K. 1979. The effect of personal taxes and dividends on capital asset prices: Theory and empirical evidence. Journal of Financial Economics 7:163-95.

Litzenberger, R. H., and Ramaswamy, K. 1980. Dividends, short selling restrictions, tax induced investor clienteles and market equilibrium. Journal of Finance 35:469-82.

Litzenberger, R. H., and Ramaswamy, K. 1982. The effects of dividends on common stock prices: Tax effects or information effects. Journal of Finance 37:429-44.

Merton, R. C. 1973. An intertemporal capital asset pricing model. Econometrica 41:86787.

Miller, M. H., and Modigliani, F. 1961. Dividend policy, growth and the valuation of shares. Journal of Business 4:411-33.

Miller, M. H., and Scholes, M. S. 1978. Dividends and taxes. Journal of Financial Economics 6:333-64. 
Miller, M. H., and Scholes, M. S. 1982. Dividends and taxes: Empirical evidence. Journal of Political Economy 90:1118-41.

Morgan, I. 1982. Dividends and capital asset prices. Journal of Finance 37:1071-86.

Poterba, J. 1986. The market valuation of cash dividends: The Citizens Utilities case reconsidered. Journal of Financial Economics 15:395-406.

Ross, S. A. 1976. The arbitrage theory of capital asset pricing. Journal of Economic Theory 13:341-60.

Rozeff, M. 1984. Dividend yields are equity risk premiums. Journal of Portfolio Management (Fall): 68-75.

White, H. 1980. A heteroscedasticity-consistent covariance matrix estimator and a direct test for heteroscedasticity. Econometrica 48:817-38. 